\title{
Extracellular vesicles in prostate cancer: a narrative review
}

\author{
Koji Hatano ${ }^{1}$, Kazutoshi Fujita ${ }^{1,2}$ \\ ${ }^{1}$ Department of Urology, Osaka University Graduate School of Medicine, Suita, Japan; ${ }^{2}$ Department of Urology, Kindai University Faculty of \\ Medicine, Osakasayama, Japan \\ Contributions: (I) Conception and design: All authors; (II) Administrative support: None; (III) Provision of study materials or patients: None; (IV) \\ Collection and assembly of data: All authors; (V) Data analysis and interpretation: All authors; (VI) Manuscript writing: All authors; (VII) Final \\ approval of manuscript: All authors. \\ Correspondence to: Kazutoshi Fujita. Department of Urology, Kindai University Faculty of Medicine, 377-2 Ohno-higashi, Osaka-Sayama, 589-8511, \\ Osaka, Japan. Email: kazufujita2@gmail.com.
}

\begin{abstract}
Over the past decade, there has been remarkable progress in prostate cancer biomarker discovery using urine- and blood-based assays. A liquid biopsy is a minimally invasive procedure to investigate the cancer-related molecules in circulating tumor cells (CTCs), cell-free DNA, and extracellular vesicles (EVs). Liquid biopsies have the advantage of detecting heterogeneity as well as acquired resistance in cancer. EVs are cell-derived vesicles enclosed by a lipid bilayer and contain various molecules, such as nucleic acids, proteins, and lipids. In patients with cancer, EVs derived from tumors can be isolated from urine, plasma, and serum. The advances in isolation techniques provide the opportunity to use EVs as biomarkers in the clinic. Emerging evidence suggests that EVs can be useful biomarkers for the diagnosis of prostate cancer, especially high-grade cancer. EVs can also be potent biomarkers for the prediction of disease progression in patients with castration-resistant prostate cancer (CRPC). EVs shed from cancer and stromal cells are involved in the development of tumor microenvironments, enhancing cancer progression, metastasis, and drug resistance. Here, we provide an overview of the use of EVs for the diagnosis of clinically significant prostate cancer as well as for predicting disease progression. We also discuss the biological function of EVs, which regulate cancer progression.
\end{abstract}

Keywords: Extracellular vesicles (EVs); exosomes; prostate cancer; biomarker; tumor microenvironment

Submitted Aug 28, 2020. Accepted for publication Dec 08, 2020.

doi: $10.21037 /$ tau-20-1210

View this article at: http://dx.doi.org/10.21037/tau-20-1210

\section{Introduction}

The number of newly diagnosed prostate cancer was estimated to be 1,276,000, and the number of deaths caused by prostate cancer was estimated to be 358,000 worldwide in 2018 (1). Histological grading using the Gleason score (GS) remains the gold standard for predicting the clinical outcome in prostate cancer (2). Randomized clinical trials demonstrated the potential benefits of radical prostatectomy in patients with $G S \geq 7(3,4)$. Further, patients with GS 9-10 are associated with an increased risk of metastasis $(5,6)$. However, prostate cancers with a GS of 6 have a low capacity for metastasis and death and are thus considered insignificant cancers $(7,8)$. To date, serum prostate-specific antigen (PSA) levels are widely used for the detection and screening of prostate cancer. However, PSA-based screening is reportedly associated with falsepositive results, biopsy complications, and overdiagnosis $(9,10)$. Thus, the development of new detection methods is required to preferentially identify patients with clinically significant prostate cancer $(\mathrm{GS} \geq 7)$ and to concurrently avoid unnecessary biopsies in men without cancer or with insignificant cancer.

Over the past decade, there has been remarkable progress in prostate cancer biomarker discovery using blood- and urine-based assays (11). The 4Kscore, including total PSA, free PSA, intact PSA, and human kallikrein 2, demonstrated excellent diagnostic performance in detecting GS $\geq 7$ prostate 
cancer (the area under receiver operating characteristic curve, AUC $=0.82)(12)$. The prostate health index, which combines total PSA, free PSA, and [-2]pro-PSA, could identify GS $\geq 7$ prostate cancer (AUC $=0.707)$ (13). The Mi-Prostate Score, which combines total serum PSA, urine transmembrane protease serine 2:v-ets erythroblastosis virus E26 oncogene homolog (TMPRSS2:ERG) fusion gene, and prostate cancer antigen 3 (PCA3) score, improved the detection of GS $\geq 7$ prostate cancer (AUC $=0.77$ ) (14). A 2-gene based urinary test that combines homeobox C6 and distal-less homeobox 1 mRNA levels could detect $\mathrm{GS} \geq 7$ prostate cancer (AUC $=0.85$ for full cohort) (15). The ExoDx Prostate IntelliScore (EPI) urine exosome assay, which includes exosomal RNA levels of PCA3, ERG, and SPDEF, improved the discrimination of $\mathrm{GS} \geq 7$ prostate cancer (16). Thus, the development of novel assays provides a significant improvement in prostate cancer diagnosis and treatment decisions.

Prostate cancer is commonly multifocal and exhibits distinctive profiles, such as allelic gains of $M Y C$, deletions of PTEN, TP53, and NKX3-1, and genomic rearrangement of TMPRSS2: ERG fusion (17-19). Furthermore, prostate cancer is a highly heterogeneous disease (20). In metastatic castration-resistant prostate cancer (CRPC), aberrations of $A R$, ETS genes, TP53, and PTEN are frequent (40-60\% of cases), and aberrations of the DNA repair genes $B R C A 2$, $B R C A 1$, and $A T M$ are substantially more frequent (20\%) in CRPCs than in primary prostate cancers (21). A liquid biopsy is a minimally invasive procedure to investigate the cancer-related molecules in circulating tumor cells (CTCs), cell-free DNA, and extracellular vesicles (EVs). Liquid biopsies have the advantage of detecting heterogeneity as well as acquired resistance in cancer (22). In this review, we focus on the use of EVs for the diagnosis of clinically significant prostate cancer as well as for predicting disease progression. We further discuss the biological function in EVs on prostate cancer progression. We present the following article in accordance with the NARRATIVE REVIEW reporting checklist (available at http://dx.doi. org/10.21037/tau-20-1210).

\section{Application of EVs for the diagnosis of prostate cancer}

EVs are classified based on their cellular origin, biological function, and biogenesis. The three main classes of EVs, which are determined by their biogenesis, are exosomes (40-120 $\mathrm{nm}$ in size), microvesicles $(50-1,000 \mathrm{~nm}$ in size), and apoptotic bodies (500-2,000 $\mathrm{nm}$ in size) (23). EVs are cell-derived vesicles enclosed by a lipid bilayer, whereas exosomes are derived from the endolysosomal pathway, and microvesicles are generated by budding from the plasma membrane $(24,25)$ (Figure 1). EVs derived from cancer cells can be isolated from bodily fluids (26-29). The advances in isolation techniques provide the opportunity to use $\mathrm{EVs}$ as biomarkers (30). Ultracentrifugation is the most common technique for EV separation and concentration, following various other techniques, such as density gradient, filtration, size-exclusion chromatography, precipitation, and magnetic bead capture (31). Protein content-based $\mathrm{EV}$ characterization is based on $\mathrm{EV}$ markers, such as tetraspanins (CD9, CD63, and CD81), flotillin-1, tumor susceptibility gene 101 (TSG101), heat-shock proteins (HSP70 and HSP90), and the major histocompatibility complex (MHC) class I and class II proteins $(32,33)$. The International Society for Extracellular Vesicles proposed guidelines for studies of EVs (34). Different EV enrichment methods yield subpopulations with different protein and RNA contents (35). Thus, the procedures for EV isolation from biofluids need to be optimized and standardized for clinical application $(35,36)$.

Sequence analysis of EVs derived from human plasma showed that microRNAs (miRNA) were the most abundant RNA species (76\%), followed by other RNA species, such as ribosomal RNA (9\%), long non-coding RNA (lncRNA, 3\%), fragments of coding sequence (1\%), and others (37). miRNAs expression alters with the development and progression of prostate cancer (38-40), and the expression of cancerrelated genes is regulated by miRNAs in prostate cancer cells (41-43). LncRNAs derived from prostate cancer EVs harbor miRNA seed regions, suggesting a function of EVs in prostate cancer progression (44). Prostate cancer cellderived EVs also carry genomic DNA fragments $(45,46)$ and contain a wide range of proteins (47). Proteomic analysis demonstrated that tumor-derived EVs have distinct protein profiles of membrane-bound and soluble proteins in prostate cancer cells (48-50). Lipids are essential components of the cellular membrane, and lipid species, such as phospholipids and glycosphingolipids, have potential to be biomarkers for malignant tumors, including prostate cancer (51-54). Lipidomic analysis revealed that specific lipid species are enriched in EVs compared to their parent cells $(55,56)$. Thus, EVs contain various molecules, including nucleic acids, proteins, and lipids (Figure 1). EVs derived from urine, plasma, serum, and semen can be potential biomarkers for the diagnosis and monitoring of prostate cancer (57-59). In this narrative review, we identified the relevant studies using 


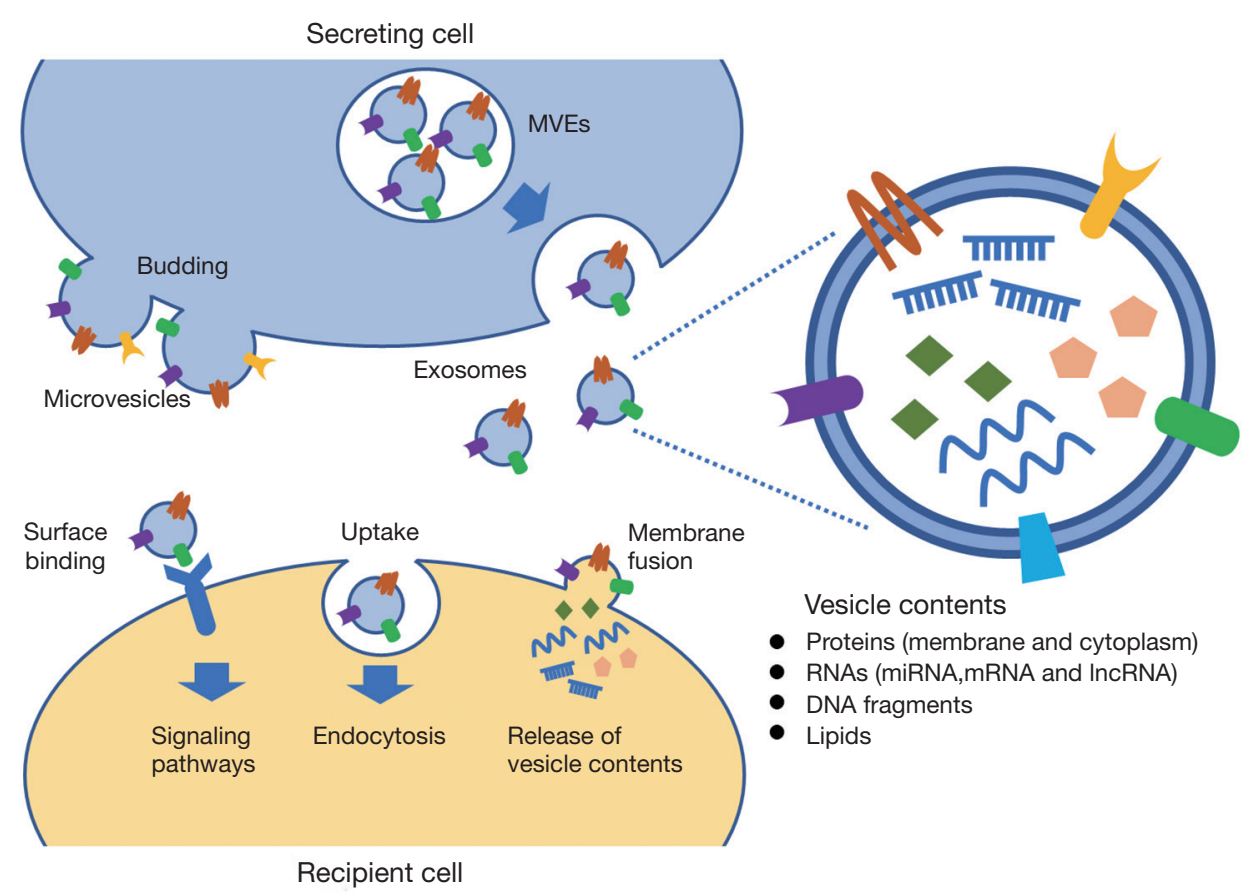

Figure 1 Biogenesis and biological function of EVs. Microvesicles are formed by budding of the plasma membrane. Exosomes are formed as intraluminal vesicles within the lumen of multivesicular endosomes (MVEs), and then, released by the fusion of MVEs with the plasma membrane. EVs are enclosed by a lipid bilayer, containing various molecules, such as proteins, nucleic acids and lipids. EVs are the mediators of intercellular communication, via the transfer of vesicle contents from the secreting cells to the recipient cells by uptake and membrane fusion. EVs also initiate intracellular signaling pathways via surface binding.

electronic databases, including PubMed, Medline and Web of Science.

\section{Urine EVs for the diagnosis of prostate cancer}

In 2009, Nilsson et al. demonstrated the presence of two prostate cancer RNA biomarkers, PCA3 and TMPRSS2:ERG, in EVs isolated from the urine of patients with prostate cancer (60). Since then, a line of evidence has suggested that urine $\mathrm{EVs}$ are useful biomarkers for the diagnosis of prostate cancer, especially high-grade cancer (Table 1).

The sum of the normalized PCA3 and ERG RNA levels in urine EVs along with the standard of care (SOC) was sufficient to discriminate $\mathrm{GS} \geq 7$ prostate cancer (AUC $=0.803$ ) (61). The EPI test, including the RNA levels of $P C A 3$ and $E R G$ in urine $\mathrm{EVs}$, in combination with SOC improved the discrimination of $\mathrm{GS} \geq 7$ prostate cancer in training $(\mathrm{n}=255)$ and validation cohorts ( $\mathrm{n}=519)$ (AUC $=0.77$ and 0.73 , respectively) (16). Although urine collected after prostate massage contains a variety of prostate cancer-derived molecules (84), the commercially available EPI test can effectively detect RNA levels in EVs from non-digital rectal examination urine samples. Further research supports the clinical value of the EPI test for the detection of high-grade prostate cancer in men presenting for initial biopsy with a PSA level of $2-10 \mathrm{ng} / \mathrm{mL}(85,86)$. The ability of urine EVs to accurately reflect prostate tissue mRNA expression was validated by comparing TMPRSS2:ERG derived from urine EVs versus corresponding radical prostatectomy tissues $(n=21)$, and the urine EVs had an overall accuracy of $81 \%$ for the noninvasive detection of TMPRSS2:ERG (64). The use of urine EVs as potential RNA biomarkers was also examined via the detection of known prostate cancer-associated genes, such as TMPRSS2:ERG, baculoviral IAP repeat containing 5 (BIRC5), ERG, PCA3, and TMPRSS2 (64). The combination of urine $\mathrm{EV}$-derived $P C A 3$ and prostate cancer susceptibility candidate (PRAC) RNA levels improved the detection of $\mathrm{GS} \geq 7$ prostate cancer (AUC $=0.736$ ) (65). Multiple gene scores, including RNA levels of GATA2 along with those of PCA3 and TMPRSS2:ERG, in urine EVs improved the 
Table 1 Urine EVs for prostate cancer diagnosis

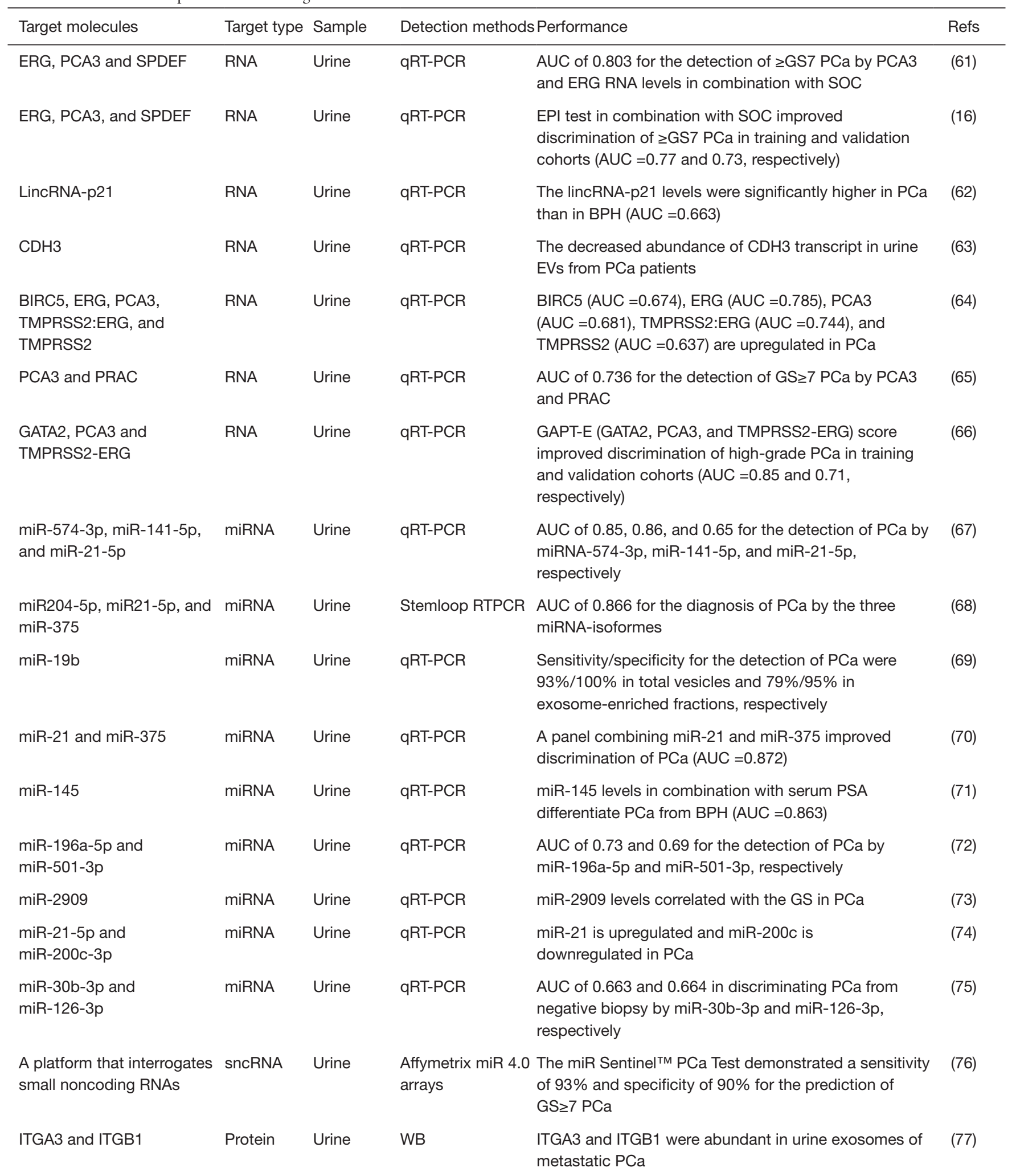

Table 1(continued) 
Table 1(continued)

\begin{tabular}{|c|c|c|c|c|c|}
\hline Target molecules & Target type & Sample & Detection methods & Performance & Refs \\
\hline CD63 & Protein & Urine & TR-FIA & $\begin{array}{l}\text { AUC of } 0.68 \text { in discriminating PCa from control } \\
\text { by CD63 }\end{array}$ & (79) \\
\hline FABP5 & Protein & Urine & SRM/MRM & $\begin{array}{l}\text { AUC of } 0.757 \text { for the detection of } \mathrm{PCa} \text {, and } \mathrm{AUC} \text { of } 0.856 \\
\text { for the detection of } \geq \mathrm{GS} 7 \mathrm{PCa}\end{array}$ & (81) \\
\hline Flotillin 2 & Protein & Urine & WB or ELISA & $\begin{array}{l}\text { AUC of } 0.91 \text { for the diagnosis of PCa by flotillin } 2 \text { using } \\
\text { western blot }\end{array}$ & (82) \\
\hline
\end{tabular}

qRT-PCR, quantitative reverse transcription-polymerase chain reaction; TR-FIA, time-resolved fluorescence immunoassay; SRM, selected reaction monitoring; MRM, multiple reaction monitoring; WB, western blotting; MS, mass spectrometry; ELISA, enzyme-linked immunosorbent assay; SOC, standard of care; EPI, ExoDx Prostate IntelliScore; PCa, prostate cancer; REF, reference.

discrimination of high-grade prostate cancer in training and validation cohorts (AUC $=0.85$ and 0.71 , respectively) (66).

A genome-wide transcriptomic analysis of urine EVs revealed transcripts with differential abundance in prostate cancer and benign prostate hyperplasia $(\mathrm{BPH})$ and identified the decreased abundance of cadherin 3, type 1 $(\mathrm{CDH} 3)$ transcript in prostate cancer-derived urine EVs (63). Long intergenic noncoding RNA-p21 (lincRNA-p21), a p53-dependent transcriptional target gene, is associated with cancer (87). The level of lincRNA-p21 derived from urine $\mathrm{EVs}$ could discriminate prostate cancer from $\mathrm{BPH}$ $(\mathrm{AUC}=0.663)(62)$.

Next-generation sequencing revealed that miRNAs have a distinct expression pattern in urine $\mathrm{EV}$ s isolated from patients with prostate cancer compared with that in urine EVs from healthy control males. The three most differentially expressed isomiRs, miR21, miR204, and miR375, were identified and had an AUC of 0.866 for the diagnostic performance in prostate cancer patients (68). Another nextgeneration sequencing study demonstrated that miR-196a-5p and miR-501-3p were downregulated in urine EVs derived from prostate cancer and had AUC values of 0.73 and 0.69, respectively, for detecting prostate cancer (72). Lectin-induced agglutination of urinary EV isolation revealed a significant upregulation of miR-574-3p, miR-141-5p, and miR-21-5p in patients with prostate cancer, with AUC values of $0.85,0.86$, and 0.65 , respectively, for detecting prostate cancer (67). Using hydrostatic filtration dialysis to isolate urine EVs effectively from patients with prostate cancer, Xu et al. revealed that miR145 levels in urine EVs combined with serum PSA could differentiate prostate cancer from BPH $(\mathrm{AUC}=0.863)(71)$. A panel combining miR-21 and miR-375 derived from urine EVs improved discrimination of prostate cancer $(\mathrm{AUC}=0.872)(70)$. Detection of miR-19b versus miR-16 in total urine EVs and exosome-enriched fractions achieved $100 \% / 93 \%$ and 95\%/79\% specificity/sensitivity, respectively, in distinguishing prostate cancer patients from healthy male (69). The levels of miR-30b-3p and miR-126-3p, which are overexpressed in urinary EVs derived from patients with prostate cancer, could discriminate patients with prostate cancer from biopsy-negative men (75). A platform that interrogates small non-coding RNAs (sncRNA) isolated from urinary EVs demonstrated a sensitivity and specificity of $93 \%$ and $90 \%$, respectively, for the prediction of $G S \geq 7$ prostate cancer (76). The miR-21 levels in urine EVs were upregulated in both non-metastatic and metastatic prostate cancer compared with those in BPH (74). The miR-2909 levels in urine EVs correlated with the GS in prostate cancer (73).

Proteomic analysis of urinary EVs by mass spectrometry identified proteins differentially expressed in patients with prostate cancer compared with the expression of these proteins in healthy male controls. The combination of transmembrane 
Table 2 Plasma and serum EVs for prostate cancer diagnosis

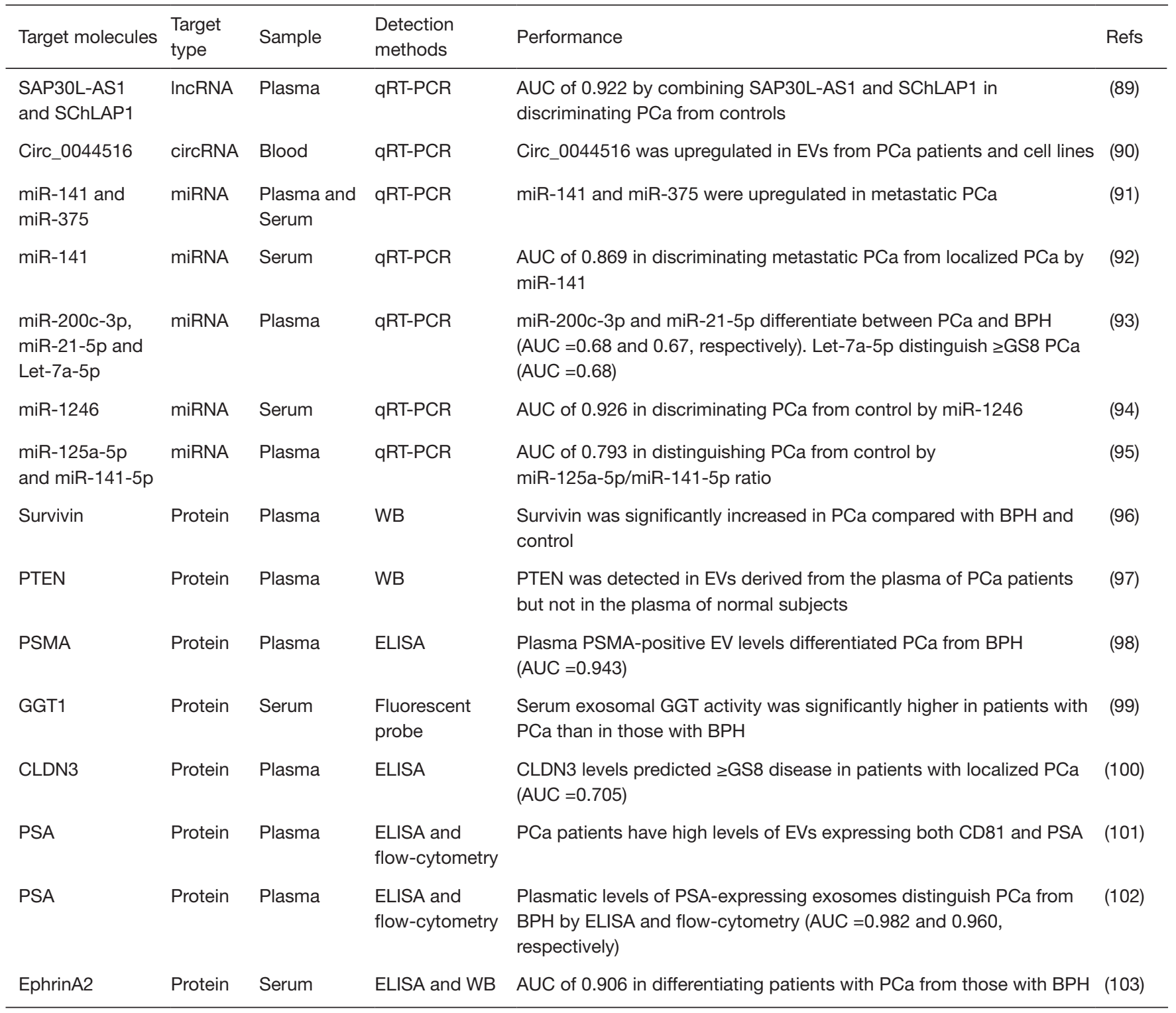

qRT-PCR, quantitative reverse transcription-polymerase chain reaction; WB, western blotting; ELISA, enzyme-linked immunosorbent assay; $\mathrm{PCa}$, prostate cancer; $\mathrm{BPH}$, benign prostatic hyperplasia; REF, reference.

protein 256 (TMEM256) and late endosomal/lysosomal adaptor, MAPK and MTOR activator 1 (LAMTOR1) provided an AUC of 0.94 for detecting prostate cancer (78). Then, antibody-based methods, such as western blotting or enzymelinked immunosorbent assay, were used to validate the proteins which were identified by the mass spectrometry; a receiver operating characteristic curve of flotillin 2 showed an AUC of 0.91 (82). Shotgun proteomics of EVs in urine by iTRAQ (isobaric tag for relative and absolute quantitation) analysis identified protein candidates for prostate cancer diagnosis (81). Subsequent analysis of these candidates by selected reaction monitoring/multiple reaction monitoring (SRM/MRM) revealed that the levels of fatty acid-binding protein 5 (FABP5) were higher in prostate cancer than in healthy individuals and could discriminate GS $\geq 7$ prostate cancer (AUC $=0.856$ ) (81). Targeted proteomics and immunoblotting techniques defined a set of protein-combination panels in urinary EVs in which a combination of CD63, glycerol kinase 5 (GK5), 
N-sulfoglucosamine sulfohydrolase (SGSH), PSA, and prostatic acid phosphatase (PPAP) had an AUC of 0.70 for the diagnosis of $\mathrm{GS} \geq 7(4+3)$ prostate cancer (80). Immuno-based detection of urine EVs by CD63 had an AUC of 0.68 (79).

Targeted metabolomics analysis of urine EVs demonstrated a variety of metabolic alterations in prostate cancer, including phosphatidylcholines, acylcarnitines, citrate, and kynurenine (88). Lipidomic analysis indicated that the lipid composition of urinary EVs, including phosphatidylserine and lactosylceramide, was significantly different between patients with prostate cancer and healthy control individuals (83).

\section{Plasma and serum EVs for the diagnosis of prostate cancer}

Plasma and serum EVs have been reported as useful biomarkers for the diagnosis of prostate cancer (Table 2).

A comprehensive qRT-PCR screening identified differentially quantified miRNAs in plasma from patients with prostate cancer (91). The expression of miR-141 and miR-375 was upregulated in plasma- and serum-derived EVs from patients with metastatic prostate cancer (91). miR-141 derived from serum EVs had an AUC of 0.869 in discriminating patients with metastatic prostate cancer from those with localized prostate cancer (92). The miR-125a-5p/miR-141-5p ratio in plasma EVs had an AUC value of 0.793 in distinguishing patients with prostate cancer (95). The EV-incorporated and whole plasma cellfree miRNA profiles were clearly different. Plasma EVs had Let-7a-5p levels that could distinguish patients with GS $\geq 8$ prostate cancer (AUC $=0.68$ ) (93). A NanoString nCounter technology revealed the profile of serum EVderived miRNAs from patients with aggressive prostate cancer and identified miR-1246 as a potential diagnostic marker (94). miR-1246 had an AUC value of 0.926 in discriminating prostate cancer from controls. miR-1246 is a tumor suppressor miRNA that is downregulated in prostate cancer clinical tissues and selectively released in EVs (94).

A lncRNA termed second chromosome locus associated with prostate-1 (SChLAP1) is overexpressed in a subset of prostate cancers, and elevated SChLAP1 levels are associated with poor outcomes (104). The combination of two lncRNAs derived from plasma EVs, SAP30L antisense RNA 1 (SAP30L-AS1), and SCbLAP1 had adequate diagnostic value to distinguish prostate cancer from controls (AUC =0.922) (89). Among circular RNAs, circ_0044516 was upregulated in EVs from patients with prostate cancer and controlled the proliferation and invasion in prostate cancer cells (90).

Plasma and serum EV-derived proteins are potential biomarkers for prostate cancer. The level of survivin isolated from plasma EVs was significantly increased in patients with prostate cancer compared with that in the controls (96). PTEN was incorporated in the cargo of EVs that circulate in the blood of patients with prostate cancer but not in the blood of healthy individuals (97). Plasma prostate-specific membrane antigen (PSMA)-positive EV concentration could differentiate prostate cancer from BPH (AUC $=0.943)(98)$. Gamma-glutamyltransferase (GGT) activity in serum EVs was significantly higher in patients with prostate cancer than in patients with BPH (99). Claudin 3 (CLDN3) levels in plasma EVs identified patients with $\mathrm{GS} \geq 8$ prostate cancer (AUC $=0.705)$ (100). The amount of plasmatic EVs expressing both CD81 and PSA was significantly higher in patients with prostate cancer than in patients with $\mathrm{BPH}$ and healthy control individuals $(101,102)$. The ephrinA2 levels in serum EVs had an AUC value of 0.906 in differentiating patients with prostate cancer from those with BPH (103).

\section{Semen EVs}

Seminal fluid contains various small membranous vesicles (105). Prostasomes, the EVs released into prostatic fluid, have been proposed to regulate spermatozoa to attain fertility $(106,107)$. Comprehensive proteomics analysis of EVs derived from seminal plasma can identify potential biomarkers for male infertility and prostate cancer (108). The miRNA profile in semen EVs was altered in patients with prostate cancer compared with that in patients with BPH. A model including serum PSA, miR-342-3p, and miR-374b-5p had an AUC of 0.891 in detecting GS $\geq 7$ prostate cancer (109).

\section{EVs as prognostic biomarkers}

EVs are considered potential biomarkers for predicting disease progression, especially in patients with CRPC (Table 3).

CTC counts can predict the prognosis of CRPC patients (122). Tumor-derived plasma EV levels were significantly increased in patients with CRPC and associated with worse overall survival $(110,111)$. The detection of androgen-receptor splice variant $7(A R-V 7)$ in CTCs from patients with CRPC was associated with resistance to enzalutamide and abiraterone (123). Likewise, the detection of $A R-V 7$ in plasma-derived $\mathrm{EV}$ s predicted resistance to 
Table 3 EVs as prognostic biomarkers of prostate cancer

\begin{tabular}{|c|c|c|c|c|c|}
\hline Target molecules & $\begin{array}{l}\text { Target } \\
\text { type }\end{array}$ & Sample & $\begin{array}{l}\text { Detection } \\
\text { methods }\end{array}$ & Performance & Refs \\
\hline Tumour-derived EVs & EVs & Blood & $\begin{array}{l}\text { ACCEPT } \\
\text { software }\end{array}$ & $\begin{array}{l}\text { CTCs and plasma levels of tumour-derived EVs were significantly } \\
\text { increased in CRPC patients compared with those in healthy donors }\end{array}$ & (110) \\
\hline Tumour-derived EVs & EVs & Blood & $\begin{array}{l}\text { ACCEPT } \\
\text { software }\end{array}$ & $\begin{array}{l}\text { Increasing tumour-derived EV counts were associated with worse OS in } \\
\text { CRPC (HR 2.2, 95\% Cl, 1.3-3.5) }\end{array}$ & (111) \\
\hline AR-V7 and AR-FL & mRNA & Urine & ddPCR & $\begin{array}{l}\text { Higher AR-V7 and lower AR-FL levels in CRPC than in hormone } \\
\text { sensitive PCa }\end{array}$ & (113) \\
\hline AR-V7 & mRNA & Plasma & ddPCR & $\begin{array}{l}\text { AR-V7-positive was associated with a shorter PFS in patients with CRPC } \\
\text { (median, } 16 \text { vs. } 28 \mathrm{mo}, \mathrm{P}=0.0499 \text { ) }\end{array}$ & (115) \\
\hline miR-1290 and miR-375 & miRNA & Plasma & qRT-PCR & $\begin{array}{l}\text { Higher levels of miR- } 1290 \text { and }-375 \text { were significantly associated with } \\
\text { poor OS in patients with CRPC }(P<0.004)\end{array}$ & (116) \\
\hline ACTN4 & Protein & Serum & $\begin{array}{l}\text { Proteomic } \\
\text { analysis }\end{array}$ & $\begin{array}{l}\text { Actinin- } 4 \text { level was increased in patients with metastatic CRPC } \\
\text { compared with that in patients with well-controlled metastatic } \\
\text { PCa receiving primary androgen deprivation therapy }\end{array}$ & (117) \\
\hline CD44v8-10 & mRNA & Serum & ddPCR & $\begin{array}{l}\text { CD44v8-10 mRNA copy numbers were higher in docetaxel-resistant } \\
\text { patients than in healthy individuals and docetaxel-naïve patients }\end{array}$ & (118) \\
\hline
\end{tabular}

AR-V7, androgen-receptor splice variant 7; AR-FL, androgen-receptor full-length; ddPCR, droplet digital polymerase chain reaction; qRT-PCR, quantitative reverse transcription-polymerase chain reaction; NGS, next-generation sequencing; CTC, circulating tumor cells; CRPC, castrate-resistant prostate cancer; PCa, prostate cancer; OS, overall survival; PFS, progression-free survival; REF, reference.

hormonal therapy in patients with CRPC $(112,114,115)$. Higher $A R-V 7$ and lower $A R$ full-length expressions were detected in urine-derived EVs from patients with CRPC compared with those in urine EVs from patients with hormone-sensitive prostate cancer (113).

RNA sequencing identified miRNAs in $\mathrm{EVs}$, which were associated with overall survival in patients with CRPC. Among them, miR-1290 and miR-375, higher levels of which were significantly associated with poor overall survival in patients with CRPC (116). Proteomic analysis of serum EVs revealed that the actinin-4 (ACTN4) level was higher in patients with metastatic CRPC than in patients with well-controlled metastatic prostate cancer who received primary androgen deprivation therapy (117). The CD44v8-10 mRNA copy numbers in serum EVs were higher in docetaxel-resistant patients than in control individuals and docetaxel-naïve patients (118). A number of miRNAs are implicated in DNA repair pathways that 


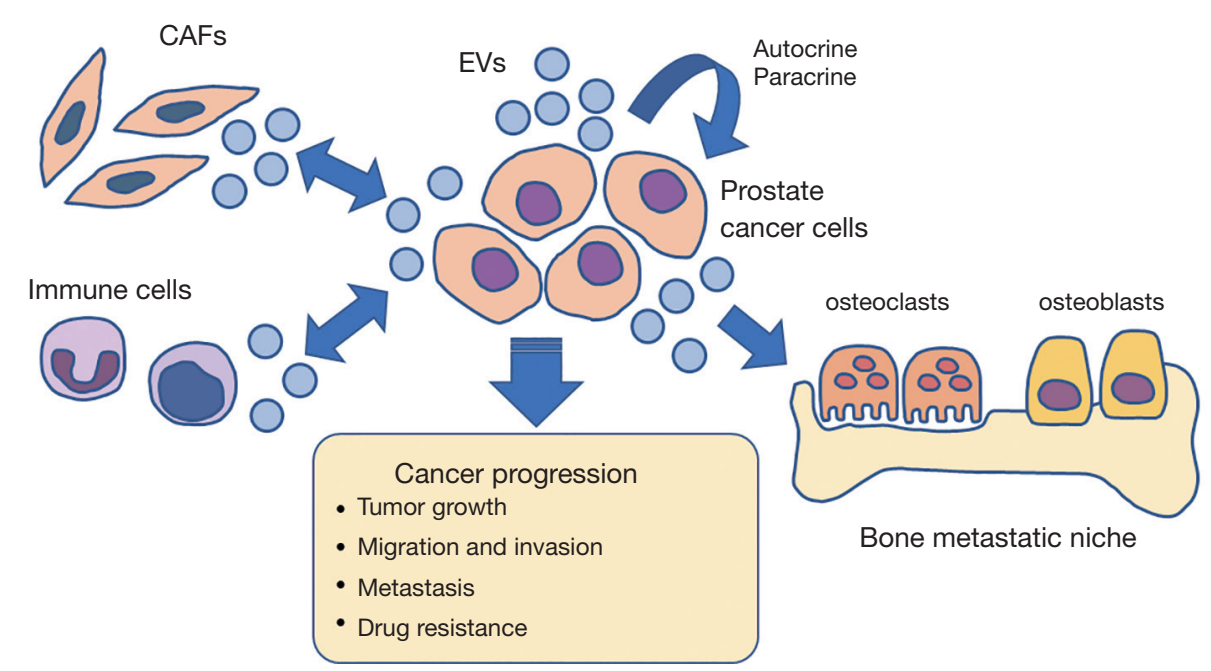

Figure 2 EVs regulate prostate tumor microenvironment. EVs shed from cancer cells and stromal cells are involved in the development of tumor microenvironment. Prostate cancer cell-derived EVs activate CAFs, in turn, CAFs shed EVs and induce proliferation, migration and invasion of cancer cells. EVs promote bone metastatic niche formation, attenuating the activity of osteoclasts and osteoblasts. EVs can enhance proliferation and invasion of tumor cells by autocrine and paracrine manner. Thus, EVs enhance cancer progression, metastasis and drug resistance. EV, extracellular vesicle; CAF, Cancer associated fibroblast.

affect radiation sensitivity (41). miRNAs in serum EVs were significantly altered after radiation therapy, indicating that they serve as potential biomarkers for predicting radiation therapy efficacy $(119,120)$. A model, comprising five urine EV miRNAs (miR-151a-5p, miR-204-5p, miR-222-3p, miR-23b-3p, and miR-331-3p) and serum PSA, significantly predicted the time to biochemical recurrence after radical prostatectomy in three independent cohorts (hazard ratio $=3.12,2.24$, and 2.15, respectively) (121). Thus, EVs may be useful to improve prostate cancer risk stratification and to guide treatment decisions.

\section{EVs are involved in tumor microenvironment formation}

Although EVs were initially considered membrane debris, in 1996, Raposo et al. reported that EVs derived from B lymphocytes induced T cell responses (124). In 2007, Valadi et al. showed that both mRNA and miRNA could be transferred between cells through EVs (125). These transferred miRNAs were shown to regulate target gene expression and recipient cell function (126-128). Since then, emerging evidence has demonstrated that EVs are important mediators of intercellular communication by transferring vesicle contents and activating signaling pathways (129-138) (Figure 1). Thus, EVs play important roles in the maintenance of normal physiology by participating in a diverse range of biological processes $(139,140)$. Furthermore, EVs are also involved in various pathological conditions, such as infectious diseases (141-143) and cancer (144-147). Emerging evidence suggests that EVs control tumor microenvironment and thus also play crucial roles in cancer development and progression (148-159).

EVs are critically involved in the development of the prostate tumor microenvironment, promoting tumor growth, invasion, bone metastasis, and drug resistance (Figure 2). Prostate cancer EVs promote the establishment of a tumor-supportive environment by inducing reprogramming of the stroma $(160,161)$. In addition, they induce the activation of fibroblasts, which in turn increase $\mathrm{EV}$ shedding and induce migration and invasion of prostate cancer cells via the CX3CL1-CX3CR1 pathway (162). Prostate cancer-derived EVs also induce migration and invasion of prostate epithelial cells via integrin $\alpha 3$ (ITGA3) and integrin $\beta 1$ (ITGB1), explaining the increased levels of ITGA3 and ITGB1 in urine EVs from patients with metastatic prostate cancer (77). Prostate cancer EVs drive fibroblast differentiation to a pro-tumorigenic phenotype via the transforming growth factor $\beta$ (TGF $\beta$ ), leading to angiogenesis and accelerated tumor growth $(163,164)$. Atypically large EVs released by prostate cancer cells enhance the migration of cancer-associated fibroblasts 
(CAFs) by intercellular transfer of functional miRNA such as miR-1227 (165). Prostate cancer EVs containing catalytically active hyaluronidase Hyal1 stimulate prostate stromal cell motility (166).

CAFs regulate the tumor microenvironment via EVs and transfer lipids and proteins to prostate cancer cells through EVs to support tumor growth (167). CAFs release miR-409 through EVs, promote epithelial-to-mesenchymal transition, and enhance prostate tumorigenesis (168). CAFderived EVs contain intact metabolites, including amino acids, lipids, and tricarboxylic acid cycle intermediates, that are utilized by cancer cells to promote tumor growth under nutrient deprivation conditions (169).

Prostate cancer cell-derived EVs are capable of inducing osteoclast differentiation and osteoblast proliferation, which attenuate bone metastasis (170). EV-derived miR-141-3p from prostate cancer cells promotes osteoblast activity, increases osteoprotegerin expression, and regulates the microenvironment of bone metastases (171). Comprehensive expression analysis identified miRNAs that were highly expressed in EVs from osteoblastic phenotypeinducing prostate cancer cell lines (172). Among them, miR940 significantly promoted the osteogenic differentiation of human mesenchymal stem cells by targeting ARHGAP1 (Rho GTPase activating protein 1) and FAM134A (family with sequence similarity 134 member A) (172). Prostate cancer-derived EVs promoted premetastatic niche formation through $\mathrm{EV}$-mediated transfer of pyruvate kinase M2 from prostate cancer cells into bone marrow stromal cells (173).

EVs secreted by tumor cells can enhance the proliferation and invasion of tumor cells in an autocrine and paracrine manner. The urokinase plasminogen activator in EVs derived from the prostate cancer cell line PC3 promotes the invasion ability of the prostate cancer cell line $\mathrm{LnCaP}$ (174). $\mathrm{EVs}$ transfer av $\beta 6$ integrin and its related functions between different subsets of prostate cancer cells, potentially promoting cell migration and metastasis (175). Hypoxia promotes prostate cancer aggressiveness by enhancing lipid accumulation in cells and EVs (176). Androgen enhances the secretion of CD9-positive EVs by prostate cancer cells to induce cancer cell proliferation (177). Nuclear translocation of AR and epidermal growth factor receptor through EVs stimulates the proliferation of prostate cancer cells (178). EVs derived from mesenchymal-like prostate cancer promote mesenchymal features in recipient epithelial-like prostate cancer cells, accompanied by a modulation of AR signaling and activation of the TGF $\beta$ signaling pathway (179).

Prostate cancer-derived EVs downregulate natural killer group 2, member D expression on natural killer and CD8+ T cells, thereby promoting immune evasion (180). Tumor-associated macrophages promote prostate cancer progression by EV-mediated transfer of miR-95 (181).

EVs expelled from docetaxel-resistant prostate cancer cells imparted docetaxel-resistance to parental prostate cancer cells by mediating the transfer of $\mathrm{P}$-glycoprotein (MDR-1) (182). The levels of miR-34a decreased in EVs of docetaxel-resistant prostate cancer cell lines, indicating that miR-34a potentially regulates the response to docetaxel by downregulating BCL-2 levels (183). As an adaptive mechanism to enzalutamide treatment, prostate cancer cells express and secrete Brain4 (BRN4) and BRN2 in EVs that drive oncogenic reprogramming of prostate cancer cells to neuroendocrine prostate cancer, an aggressive variant of CRPC (184).

Thus, EVs shed from cancer and stromal cells contribute to the generation of the tumor microenvironment and enhance cancer progression, metastasis, and drug resistance. The cargo of $\mathrm{EV}$ includes various molecules, and $\mathrm{EV}$ is also useful as a drug delivery system (185-187). The advances in $\mathrm{EV}$ isolation techniques may further promote the potential use of EVs as biomarkers in the clinic.

\section{Conclusions}

EVs derived from cancer cells and stromal cells can be isolated from bodily fluids, such as urine, plasma, serum, and semen. EVs are considered useful biomarkers for detecting clinically significant prostate cancer. EVs can also be used as potential biomarkers for the prediction of disease progression and the monitoring of prostate cancer. Although the EPI test has been clinically validated for the detection of high-grade prostate cancer, the other methods still need further validation. EVs contribute to the formation of the prostate tumor microenvironment and enhance tumor proliferation, invasion, bone metastasis, and drug resistance. Future studies are needed to uncover the mechanism of cancer progression mediated by EVs.

\section{Acknowledgments}

We would like to thank Editage (www.editage.com) for English language editing. 
Funding: This work was supported by the Japan Society for the Promotion of Science KAKENHI [grant numbers 20K18090 and T18K091320].

\section{Footnote}

Provenance and Peer Review: This article was commissioned by the editorial office, Translational Andrology and Urology for the series "Urinary Biomarkers of Urothelial Malignancies". The article has undergone external peer review.

Reporting Checklist: The authors have completed the NARRATIVE REVIEW reporting checklist. Available at http://dx.doi.org/10.21037/tau-20-1210

Conflicts of Interest: Both authors have completed the ICMJE uniform disclosure form (available at http:// dx.doi.org/10.21037/tau-20-1210). The series "Urinary Biomarkers of Urothelial Malignancies" was commissioned by the editorial office without any funding or sponsorship. KF serves as an unpaid editorial board member of Translational Andrology and Urology from Oct 2019 to Sep 2021 and served as the unpaid Guest Editor of the series. The authors have no other conflicts of interest to declare.

Ethical Statement: The authors are accountable for all aspects of the work in ensuring that questions related to the accuracy or integrity of any part of the work are appropriately investigated and resolved.

Open Access Statement: This is an Open Access article distributed in accordance with the Creative Commons Attribution-NonCommercial-NoDerivs 4.0 International License (CC BY-NC-ND 4.0), which permits the noncommercial replication and distribution of the article with the strict proviso that no changes or edits are made and the original work is properly cited (including links to both the formal publication through the relevant DOI and the license). See: https://creativecommons.org/licenses/by-nc-nd/4.0/.

\section{References}

1. Bray F, Ferlay J, Soerjomataram I, et al. Global cancer statistics 2018: GLOBOCAN estimates of incidence and mortality worldwide for 36 cancers in 185 countries. CA Cancer J Clin 2018;68:394-424.

2. Epstein JI, Egevad L, Amin MB, et al. The 2014 International Society of Urological Pathology (ISUP)
Consensus Conference on Gleason Grading of Prostatic Carcinoma: Definition of Grading Patterns and Proposal for a New Grading System. Am J Surg Pathol 2016;40:244-52.

3. Wilt TJ, Brawer MK, Jones KM, et al. Radical prostatectomy versus observation for localized prostate cancer. N Engl J Med 2012;367:203-13.

4. Bill-Axelson A, Holmberg L, Garmo H, et al. Radical prostatectomy or watchful waiting in early prostate cancer. N Engl J Med 2014;370:932-42.

5. Kishan AU, Cook RR, Ciezki JP, et al. Radical Prostatectomy, External Beam Radiotherapy, or External Beam Radiotherapy With Brachytherapy Boost and Disease Progression and Mortality in Patients With Gleason Score 9-10 Prostate Cancer. JAMA 2018;319:896-905.

6. Hatano K, Tanaka J, Nakai Y, et al. Utility of index lesion volume assessed by multiparametric MRI combined with Gleason grade for assessment of lymph node involvement in patients with high-risk prostate cancer. Jpn J Clin Oncol 2020;50:333-7.

7. Ross HM, Kryvenko ON, Cowan JE, et al. Do adenocarcinomas of the prostate with Gleason score (GS) $\leq 6$ have the potential to metastasize to lymph nodes? Am J Surg Pathol 2012;36:1346-52.

8. Liu JJ, Lichtensztajn DY, Gomez SL, et al. Nationwide prevalence of lymph node metastases in Gleason score $3+3=6$ prostate cancer. Pathology 2014;46:306-10.

9. Fenton JJ, Weyrich MS, Durbin S, et al. Prostate-Specific Antigen-Based Screening for Prostate Cancer: Evidence Report and Systematic Review for the US Preventive Services Task Force. JAMA 2018;319:1914-31.

10. Srivastava S, Koay EJ, Borowsky AD, et al. Cancer overdiagnosis: a biological challenge and clinical dilemma. Nat Rev Cancer 2019;19:349-58.

11. Kohaar I, Petrovics G, Srivastava S. A Rich Array of Prostate Cancer Molecular Biomarkers: Opportunities and Challenges. Int J Mol Sci 2019;20:1813.

12. Parekh DJ, Punnen S, Sjoberg DD, et al. A multiinstitutional prospective trial in the USA confirms that the 4Kscore accurately identifies men with high-grade prostate cancer. Eur Urol 2015;68:464-70.

13. Loeb S, Sanda MG, Broyles DL, et al. The prostate health index selectively identifies clinically significant prostate cancer. J Urol 2015;193:1163-9.

14. Tomlins SA, Day JR, Lonigro RJ, et al. Urine TMPRSS2:ERG Plus PCA3 for Individualized Prostate Cancer Risk Assessment. Eur Urol 2016;70:45-53. 
15. Haese A, Trooskens G, Steyaert S, et al. Multicenter Optimization and Validation of a 2-Gene mRNA Urine Test for Detection of Clinically Significant Prostate Cancer before Initial Prostate Biopsy. J Urol 2019;202:256-63.

16. McKiernan J, Donovan MJ, O’Neill V, et al. A Novel Urine Exosome Gene Expression Assay to Predict Highgrade Prostate Cancer at Initial Biopsy. JAMA Oncol 2016;2:882-9.

17. Cooper CS, Eeles R, Wedge DC, et al. Analysis of the genetic phylogeny of multifocal prostate cancer identifies multiple independent clonal expansions in neoplastic and morphologically normal prostate tissue. Nat Genet 2015;47:367-72.

18. Boutros PC, Fraser M, Harding NJ, et al. Spatial genomic heterogeneity within localized, multifocal prostate cancer. Nat Genet 2015;47:736-45.

19. Fraser M, Sabelnykova VY, Yamaguchi TN, et al. Genomic hallmarks of localized, non-indolent prostate cancer. Nature 2017;541:359-64.

20. Gundem G, Van Loo P, Kremeyer B, et al. The evolutionary history of lethal metastatic prostate cancer. Nature 2015;520:353-7.

21. Robinson D, Van Allen EM, Wu Y-M, et al. Integrative clinical genomics of advanced prostate cancer. Cell 2015;161:1215-28.

22. Parikh AR, Leshchiner I, Elagina L, et al. Liquid versus tissue biopsy for detecting acquired resistance and tumor heterogeneity in gastrointestinal cancers. Nat Med 2019;25:1415-21.

23. EL Andaloussi S, Mäger I, Breakefield XO, et al. Extracellular vesicles: biology and emerging therapeutic opportunities. Nat Rev Drug Discov 2013;12:347-57.

24. Hessvik NP, Llorente A. Current knowledge on exosome biogenesis and release. Cell Mol Life Sci 2018;75:193-208.

25. van Niel G, D’Angelo G, Raposo G. Shedding light on the cell biology of extracellular vesicles. Nat Rev Mol Cell Biol 2018;19:213-28.

26. Simpson RJ, Lim JW, Moritz RL, et al. Exosomes: proteomic insights and diagnostic potential. Expert Rev Proteomics 2009;6:267-83.

27. Raimondo F, Morosi L, Chinello C, et al. Advances in membranous vesicle and exosome proteomics improving biological understanding and biomarker discovery. Proteomics 2011;11:709-20.

28. Rak J. Extracellular vesicles - biomarkers and effectors of the cellular interactome in cancer. Front Pharmacol 2013;4:21.

29. Verma M, Lam TK, Hebert E, et al. Extracellular vesicles: potential applications in cancer diagnosis, prognosis, and epidemiology. BMC Clin Pathol 2015;15:6.

30. Li P, Kaslan M, Lee SH, et al. Progress in Exosome Isolation Techniques. Theranostics 2017;7:789-804.

31. Gardiner C, Di Vizio D, Sahoo S, et al. Techniques used for the isolation and characterization of extracellular vesicles: results of a worldwide survey. J Extracell Vesicles 2016;5:32945.

32. Yoshioka Y, Konishi Y, Kosaka N, et al. Comparative marker analysis of extracellular vesicles in different human cancer types. J Extracell Vesicles 2013;2. doi: 10.3402/jev. v2i0.20424.

33. Kowal J, Arras G, Colombo M, et al. Proteomic comparison defines novel markers to characterize heterogeneous populations of extracellular vesicle subtypes. Proc Natl Acad Sci USA 2016;113:E968-977.

34. Théry C, Witwer KW, Aikawa E, et al. Minimal information for studies of extracellular vesicles 2018 (MISEV2018): a position statement of the International Society for Extracellular Vesicles and update of the MISEV2014 guidelines. J Extracell Vesicles 2018;7:1535750.

35. Royo F, Zuñiga-Garcia P, Sanchez-Mosquera P, et al. Different EV enrichment methods suitable for clinical settings yield different subpopulations of urinary extracellular vesicles from human samples. J Extracell Vesicles 2016;5:29497.

36. Ramirez MI, Amorim MG, Gadelha C, et al. Technical challenges of working with extracellular vesicles. Nanoscale 2018;10:881-906.

37. Huang X, Yuan T, Tschannen M, et al. Characterization of human plasma-derived exosomal RNAs by deep sequencing. BMC Genomics 2013;14:319.

38. Porkka KP, Pfeiffer MJ, Waltering KK, et al. MicroRNA expression profiling in prostate cancer. Cancer Res 2007;67:6130-5.

39. Ambs S, Prueitt RL, Yi M, et al. Genomic profiling of microRNA and messenger RNA reveals deregulated microRNA expression in prostate cancer. Cancer Res 2008;68:6162-70.

40. Moltzahn F, Olshen AB, Baehner L, et al. Microfluidicbased multiplex qRT-PCR identifies diagnostic and prognostic microRNA signatures in the sera of prostate cancer patients. Cancer Res 2011;71:550-60.

41. Hatano K, Kumar B, Zhang Y, et al. A functional screen identifies miRNAs that inhibit DNA repair and sensitize prostate cancer cells to ionizing radiation. Nucleic Acids Res 2015;43:4075-86. 
42. Kumar B, Khaleghzadegan S, Mears B, et al. Identification of $\mathrm{miR}-30 \mathrm{~b}-3 \mathrm{p}$ and $\mathrm{miR}-30 \mathrm{~d}-5 \mathrm{p}$ as direct regulators of androgen receptor signaling in prostate cancer by complementary functional microRNA library screening. Oncotarget 2016;7:72593-607.

43. Zennami K, Choi SM, Liao R, et al. PDCD4 Is an Androgen-Repressed Tumor Suppressor that Regulates Prostate Cancer Growth and Castration Resistance. Mol Cancer Res 2019;17:618-27.

44. Ahadi A, Brennan S, Kennedy PJ, et al. Long non-coding RNAs harboring miRNA seed regions are enriched in prostate cancer exosomes. Sci Rep 2016;6:24922.

45. Lázaro-Ibáñez E, Sanz-Garcia A, Visakorpi T, et al. Different gDNA content in the subpopulations of prostate cancer extracellular vesicles: apoptotic bodies, microvesicles, and exosomes. Prostate 2014;74:1379-90.

46. Vagner T, Spinelli C, Minciacchi VR, et al. Large extracellular vesicles carry most of the tumour DNA circulating in prostate cancer patient plasma. J Extracell Vesicles 2018;7:1505403.

47. Martins VR, Dias MS, Hainaut P. Tumor-cell-derived microvesicles as carriers of molecular information in cancer. Curr Opin Oncol 2013;25:66-75.

48. Duijvesz D, Burnum-Johnson KE, Gritsenko MA, et al. Proteomic profiling of exosomes leads to the identification of novel biomarkers for prostate cancer. PLoS One 2013;8:e82589.

49. Webber J, Stone TC, Katilius E, et al. Proteomics analysis of cancer exosomes using a novel modified aptamer-based array (SOMAscanTM) platform. Mol Cell Proteomics 2014;13:1050-64.

50. Minciacchi VR, You S, Spinelli C, et al. Large oncosomes contain distinct protein cargo and represent a separate functional class of tumor-derived extracellular vesicles. Oncotarget 2015;6:11327-41.

51. Hatano K, Miyamoto Y, Nonomura N, et al. Expression of gangliosides, GD1a, and sialyl paragloboside is regulated by NF- $\kappa \mathrm{B}$-dependent transcriptional control of $\alpha 2,3-$ sialyltransferase I, II, and VI in human castration-resistant prostate cancer cells. Int J Cancer 2011;129:1838-47.

52. Hatano K, Miyamoto Y, Mori M, et al. Androgenregulated transcriptional control of sialyltransferases in prostate cancer cells. PLoS One 2012;7:e31234.

53. Bandu R, Mok HJ, Kim KP. Phospholipids as cancer biomarkers: Mass spectrometry-based analysis. Mass Spectrom Rev 2018;37:107-38.

54. Furukawa K, Ohmi Y, Ohkawa Y, et al. New era of research on cancer-associated glycosphingolipids. Cancer
Sci 2019;110:1544-51.

55. Llorente A, Skotland T, Sylvänne T, et al. Molecular lipidomics of exosomes released by PC-3 prostate cancer cells. Biochim Biophys Acta 2013;1831:1302-9.

56. Skotland T, Sandvig K, Llorente A. Lipids in exosomes: Current knowledge and the way forward. Prog Lipid Res 2017;66:30-41.

57. Nawaz M, Camussi G, Valadi H, et al. The emerging role of extracellular vesicles as biomarkers for urogenital cancers. Nat Rev Urol 2014;11:688-701.

58. Junker K, Heinzelmann J, Beckham C, et al. Extracellular Vesicles and Their Role in Urologic Malignancies. Eur Urol 2016;70:323-31.

59. Urabe F, Kosaka N, Kimura T, et al. Extracellular vesicles: Toward a clinical application in urological cancer treatment. Int J Urol 2018;25:533-43.

60. Nilsson J, Skog J, Nordstrand A, et al. Prostate cancerderived urine exosomes: a novel approach to biomarkers for prostate cancer. Br J Cancer 2009;100:1603-7.

61. Donovan MJ, Noerholm M, Bentink S, et al. A molecular signature of PCA3 and ERG exosomal RNA from nonDRE urine is predictive of initial prostate biopsy result. Prostate Cancer Prostatic Dis 2015;18:370-5.

62. Işın M, Uysaler E, Özgür E, et al. Exosomal lncRNA-p21 levels may help to distinguish prostate cancer from benign disease. Front Genet 2015;6:168.

63. Royo F, Zuñiga-Garcia P, Torrano V, et al. Transcriptomic profiling of urine extracellular vesicles reveals alterations of CDH3 in prostate cancer. Oncotarget 2016;7:6835-46.

64. Motamedinia P, Scott AN, Bate KL, et al. Urine Exosomes for Non-Invasive Assessment of Gene Expression and Mutations of Prostate Cancer. PLoS ONE 2016;11:e0154507.

65. Ye LF, He S, Wu X, et al. Detection of Prostate Cancer Antigen 3 and Prostate Cancer Susceptibility Candidate in Non-DRE Urine Improves Diagnosis of Prostate Cancer in Chinese Population. Prostate Cancer 2020;2020:3964615.

66. Woo J, Santasusagna S, Banks J, et al. Urine Extracellular Vesicle GATA2 mRNA Discriminates Biopsy Result in Men with Suspicion of Prostate Cancer. J Urol 2020;204:691-700.

67. Samsonov R, Shtam T, Burdakov V, et al. Lectin-induced agglutination method of urinary exosomes isolation followed by mi-RNA analysis: Application for prostate cancer diagnostic. Prostate 2016;76:68-79.

68. Koppers-Lalic D, Hackenberg M, de Menezes R, et al. Non-invasive prostate cancer detection by measuring 
miRNA variants (isomiRs) in urine extracellular vesicles. Oncotarget 2016;7:22566-78.

69. Bryzgunova OE, Zaripov MM, Skvortsova TE, et al. Comparative Study of Extracellular Vesicles from the Urine of Healthy Individuals and Prostate Cancer Patients. PLoS One 2016;11:e0157566.

70. Foj L, Ferrer F, Serra M, et al. Exosomal and NonExosomal Urinary miRNAs in Prostate Cancer Detection and Prognosis. Prostate 2017;77:573-83.

71. Xu Y, Qin S, An T, et al. MiR-145 detection in urinary extracellular vesicles increase diagnostic efficiency of prostate cancer based on hydrostatic filtration dialysis method. Prostate 2017;77:1167-75.

72. Rodríguez M, Bajo-Santos C, Hessvik NP, et al. Identification of non-invasive miRNAs biomarkers for prostate cancer by deep sequencing analysis of urinary exosomes. Mol Cancer 2017;16:156.

73. Wani S, Kaul D, Mavuduru RS, et al. Urinary-exosomal miR-2909: A novel pathognomonic trait of prostate cancer severity. J Biotechnol 2017;259:135-9.

74. Danarto R, Astuti I, Umbas R, et al. Urine miR-21-5p and miR-200c-3p as potential non-invasive biomarkers in patients with prostate cancer. Turk J Urol 2019;46:26-30.

75. Matsuzaki K, Fujita K, Tomiyama E, et al. MiR-30b-3p and miR-126-3p of urinary extracellular vesicles could be new biomarkers for prostate cancer. Transl Androl Urol 2021;10:1918-27.

76. Wang WW, Sorokin I, Aleksic I, et al. Expression of Small Noncoding RNAs in Urinary Exosomes Classifies Prostate Cancer into Indolent and Aggressive Disease. J Urol 2020;204:466-75.

77. Bijnsdorp IV, Geldof AA, Lavaei M, et al. Exosomal ITGA3 interferes with non-cancerous prostate cell functions and is increased in urine exosomes of metastatic prostate cancer patients. J Extracell Vesicles 2013;2. doi: 10.3402/jev.v2i0.22097.

78. Øverbye A, Skotland T, Koehler CJ, et al. Identification of prostate cancer biomarkers in urinary exosomes. Oncotarget 2015;6:30357-76.

79. Duijvesz D, Versluis CYL, van der Fels CAM, et al. Immuno-based detection of extracellular vesicles in urine as diagnostic marker for prostate cancer. Int J Cancer 2015;137:2869-78.

80. Sequeiros T, Rigau M, Chiva C, et al. Targeted proteomics in urinary extracellular vesicles identifies biomarkers for diagnosis and prognosis of prostate cancer. Oncotarget 2017;8:4960-76.

81. Fujita K, Kume H, Matsuzaki K, et al. Proteomic analysis of urinary extracellular vesicles from high Gleason score prostate cancer. Sci Rep 2017;7:42961.

82. Wang L, Skotland T, Berge V, et al. Exosomal proteins as prostate cancer biomarkers in urine: From mass spectrometry discovery to immunoassay-based validation. Eur J Pharm Sci 2017;98:80-5.

83. Skotland T, Ekroos K, Kauhanen D, et al. Molecular lipid species in urinary exosomes as potential prostate cancer biomarkers. Eur J Cancer 2017;70:122-32.

84. Fujita K, Nonomura N. Urinary biomarkers of prostate cancer. Int J Urol 2018;25:770-9.

85. McKiernan J, Donovan MJ, Margolis E, et al. A Prospective Adaptive Utility Trial to Validate Performance of a Novel Urine Exosome Gene Expression Assay to Predict High-grade Prostate Cancer in Patients with Prostate-specific Antigen 2-10ng/ml at Initial Biopsy. Eur Urol 2018;74:731-8.

86. Tutrone R, Donovan MJ, Torkler P, et al. Clinical utility of the exosome based ExoDx Prostate(IntelliScore) EPI test in men presenting for initial Biopsy with a PSA 2-10 ng/ mL. Prostate Cancer Prostatic Dis 2020;23:607-14.

87. Chen S, Liang H, Yang H, et al. LincRNa-p21: function and mechanism in cancer. Med Oncol 2017;34:98.

88. Clos-Garcia M, Loizaga-Iriarte A, Zuñiga-Garcia P, et al. Metabolic alterations in urine extracellular vesicles are associated to prostate cancer pathogenesis and progression. J Extracell Vesicles 2018;7:1470442.

89. Wang YH, Ji J, Wang BC, et al. Tumor-Derived Exosomal Long Noncoding RNAs as Promising Diagnostic Biomarkers for Prostate Cancer. Cell Physiol Biochem 2018;46:532-45.

90. Li T, Sun X, Chen L. Exosome circ_0044516 promotes prostate cancer cell proliferation and metastasis as a potential biomarker. J Cell Biochem 2020;121:2118-26.

91. Bryant RJ, Pawlowski T, Catto JWF, et al. Changes in circulating microRNA levels associated with prostate cancer. Br J Cancer 2012;106:768-74.

92. Li Z, Ma YY, Wang J, et al. Exosomal microRNA-141 is upregulated in the serum of prostate cancer patients. Onco Targets Ther 2015;9:139-48.

93. Endzeliņš E, Berger A, Melne V, et al. Detection of circulating miRNAs: comparative analysis of extracellular vesicle-incorporated miRNAs and cell-free miRNAs in whole plasma of prostate cancer patients. BMC Cancer 2017;17:730.

94. Bhagirath D, Yang TL, Bucay N, et al. microRNA-1246 Is an Exosomal Biomarker for Aggressive Prostate Cancer. Cancer Res 2018;78:1833-44. 
95. Li W, Dong Y, Wang KJ, et al. Plasma exosomal miR$125 a-5 p$ and miR-141-5p as non-invasive biomarkers for prostate cancer. Neoplasma 2020;67:1314-8.

96. Khan S, Jutzy JMS, Valenzuela MMA, et al. Plasmaderived exosomal survivin, a plausible biomarker for early detection of prostate cancer. PLoS ONE 2012;7:e46737.

97. Gabriel K, Ingram A, Austin R, et al. Regulation of the tumor suppressor PTEN through exosomes: a diagnostic potential for prostate cancer. PLoS ONE 2013;8:e70047.

98. Park YH, Shin HW, Jung AR, et al. Prostate-specific extracellular vesicles as a novel biomarker in human prostate cancer. Sci Rep 2016;6:30386.

99. Kawakami K, Fujita Y, Matsuda Y, et al. Gammaglutamyltransferase activity in exosomes as a potential marker for prostate cancer. BMC Cancer 2017;17:316.

100. Worst TS, von Hardenberg J, Gross JC, et al. Databaseaugmented Mass Spectrometry Analysis of Exosomes Identifies Claudin 3 as a Putative Prostate Cancer Biomarker. Mol Cell Proteomics 2017;16:998-1008.

101.Logozzi M, Angelini DF, Iessi E, et al. Increased PSA expression on prostate cancer exosomes in in vitro condition and in cancer patients. Cancer Lett 2017;403:318-29.

102.Logozzi M, Angelini DF, Giuliani A, et al. Increased Plasmatic Levels of PSA-Expressing Exosomes Distinguish Prostate Cancer Patients from Benign Prostatic Hyperplasia: A Prospective Study. Cancers (Basel) 2019;11:1449.

103.Li S, Zhao Y, Chen W, et al. Exosomal ephrinA2 derived from serum as a potential biomarker for prostate cancer. J Cancer 2018;9:2659-65.

104. Prensner JR, Iyer MK, Sahu A, et al. The long noncoding RNA SChLAP1 promotes aggressive prostate cancer and antagonizes the SWI/SNF complex. Nat Genet 2013;45:1392-8.

105. Aalberts M, van Dissel-Emiliani FMF, van Adrichem $\mathrm{NPH}$, et al. Identification of distinct populations of prostasomes that differentially express prostate stem cell antigen, annexin A1, and GLIPR2 in humans. Biol Reprod 2012;86:82.

106. Ronquist G. Prostasomes are mediators of intercellular communication: from basic research to clinical implications. J Intern Med 2012;271:400-13.

107.Aalberts M, Stout TAE, Stoorvogel W. Prostasomes: extracellular vesicles from the prostate. Reproduction 2013;147:R1-14.

108. Yang C, Guo W-B, Zhang W-S, et al. Comprehensive proteomics analysis of exosomes derived from human seminal plasma. Andrology 2017;5:1007-15.

109. Barceló M, Castells M, Bassas L, et al. Semen miRNAs Contained in Exosomes as Non-Invasive Biomarkers for Prostate Cancer Diagnosis. Sci Rep 2019;9:13772.

110. Nanou A, Coumans FAW, van Dalum G, et al. Circulating tumor cells, tumor-derived extracellular vesicles and plasma cytokeratins in castration-resistant prostate cancer patients. Oncotarget 2018;9:19283-93.

111. Nanou A, Miller MC, Zeune LL, et al. Tumour-derived extracellular vesicles in blood of metastatic cancer patients associate with overall survival. Br J Cancer 2020;122:801-11.

112.Del Re M, Biasco E, Crucitta S, et al. The Detection of Androgen Receptor Splice Variant 7 in Plasma-derived Exosomal RNA Strongly Predicts Resistance to Hormonal Therapy in Metastatic Prostate Cancer Patients. Eur Urol 2017;71:680-7.

113. Woo H-K, Park J, Ku JY, et al. Urine-based liquid biopsy: non-invasive and sensitive AR-V7 detection in urinary EVs from patients with prostate cancer. Lab Chip 2018;19:87-97.

114.Del Re M, Crucitta S, Sbrana A, et al. AR-V7 and ARFL expression is associated with clinical outcome: a translational study in patients with castrate resistant prostate cancer. BJU Int 2019 (in press).

115.Joncas F-H, Lucien F, Rouleau M, et al. Plasma extracellular vesicles as phenotypic biomarkers in prostate cancer patients. Prostate 2019;79:1767-76.

116. Huang X, Yuan T, Liang M, et al. Exosomal miR-1290 and miR-375 as prognostic markers in castration-resistant prostate cancer. Eur Urol 2015;67:33-41.

117.Ishizuya $Y$, Uemura $M$, Narumi R, et al. The role of actinin-4 (ACTN4) in exosomes as a potential novel therapeutic target in castration-resistant prostate cancer. Biochem Biophys Res Commun 2020;523:588-94.

118. Kato T, Mizutani K, Kawakami K, et al. CD44v8-10 mRNA contained in serum exosomes as a diagnostic marker for docetaxel resistance in prostate cancer patients. Heliyon 2020;6:e04138.

119.Yu Q, Li P, Weng M, et al. Nano-Vesicles are a Potential Tool to Monitor Therapeutic Efficacy of Carbon Ion Radiotherapy in Prostate Cancer. J Biomed Nanotechnol 2018;14:168-78.

120.Malla B, Aebersold DM, Dal Pra A. Protocol for serum exosomal miRNAs analysis in prostate cancer patients treated with radiotherapy. J Transl Med 2018;16:223.

121. Fredsøe J, Rasmussen AKI, Mouritzen P, et al. A fivemicroRNA model ( $\mathrm{pCaP}$ ) for predicting prostate 
cancer aggressiveness using cell-free urine. Int J Cancer 2019;145:2558-67.

122. de Bono JS, Scher HI, Montgomery RB, et al. Circulating tumor cells predict survival benefit from treatment in metastatic castration-resistant prostate cancer. Clin Cancer Res 2008;14:6302-9.

123. Antonarakis ES, Lu C, Wang H, et al. AR-V7 and resistance to enzalutamide and abiraterone in prostate cancer. N Engl J Med 2014;371:1028-38.

124. Raposo G, Nijman HW, Stoorvogel W, et al. B lymphocytes secrete antigen-presenting vesicles. J Exp Med 1996;183:1161-72.

125. Valadi H, Ekström K, Bossios A, et al. Exosome-mediated transfer of mRNAs and microRNAs is a novel mechanism of genetic exchange between cells. Nat Cell Biol 2007;9:654-9.

126.Pegtel DM, Cosmopoulos K, Thorley-Lawson DA, et al. Functional delivery of viral miRNAs via exosomes. Proc Natl Acad Sci USA 2010;107:6328-33.

127.Kosaka N, Iguchi H, Yoshioka Y, et al. Secretory mechanisms and intercellular transfer of microRNAs in living cells. J Biol Chem 2010;285:17442-52.

128. Zhang Y, Liu D, Chen X, et al. Secreted monocytic miR150 enhances targeted endothelial cell migration. Mol Cell 2010;39:133-44.

129.Denzer K, Kleijmeer MJ, Heijnen HF, et al. Exosome: from internal vesicle of the multivesicular body to intercellular signaling device. J Cell Sci 2000;113:3365-74.

130.Février B, Raposo G. Exosomes: endosomal-derived vesicles shipping extracellular messages. Curr Opin Cell Biol 2004;16:415-21.

131.van Niel G, Porto-Carreiro I, Simoes S, et al. Exosomes: a common pathway for a specialized function. J Biochem 2006;140:13-21.

132. Simpson RJ, Jensen SS, Lim JWE. Proteomic profiling of exosomes: current perspectives. Proteomics 2008;8:4083-99.

133. Simons M, Raposo G. Exosomes--vesicular carriers for intercellular communication. Curr Opin Cell Biol 2009;21:575-81.

134. Théry C, Ostrowski M, Segura E. Membrane vesicles as conveyors of immune responses. Nat Rev Immunol 2009;9:581-93.

135. Chaput N, Théry C. Exosomes: immune properties and potential clinical implementations. Semin Immunopathol 2011;33:419-40.

136. Bobrie A, Colombo M, Raposo G, et al. Exosome secretion: molecular mechanisms and roles in immune responses. Traffic 2011;12:1659-68.

137.Lee Y, El Andaloussi S, Wood MJA. Exosomes and microvesicles: extracellular vesicles for genetic information transfer and gene therapy. Hum Mol Genet 2012;21:R125-134.

138. Raposo G, Stoorvogel W. Extracellular vesicles: exosomes, microvesicles, and friends. J Cell Biol 2013;200:373-83.

139. Heijnen HF, Schiel AE, Fijnheer R, et al. Activated platelets release two types of membrane vesicles: microvesicles by surface shedding and exosomes derived from exocytosis of multivesicular bodies and alphagranules. Blood 1999;94:3791-9.

140. Fauré J, Lachenal G, Court M, et al. Exosomes are released by cultured cortical neurones. Mol Cell Neurosci 2006;31:642-8.

141. Mack M, Kleinschmidt A, Brühl H, et al. Transfer of the chemokine receptor CCR5 between cells by membranederived microparticles: a mechanism for cellular human immunodeficiency virus 1 infection. Nat Med 2000;6:769-75.

142.Lenassi M, Cagney G, Liao M, et al. HIV Nef is secreted in exosomes and triggers apoptosis in bystander CD4+ T cells. Traffic 2010;11:110-22.

143. Robbins PD, Morelli AE. Regulation of immune responses by extracellular vesicles. Nat Rev Immunol 2014;14:195-208.

144.Koga K, Matsumoto K, Akiyoshi T, et al. Purification, characterization and biological significance of tumorderived exosomes. Anticancer Res 2005;25:3703-7.

145. Hannafon BN, Ding W-Q. Intercellular communication by exosome-derived microRNAs in cancer. Int J Mol Sci 2013;14:14240-69.

146. Kosaka N, Yoshioka Y, Fujita Y, et al. Versatile roles of extracellular vesicles in cancer. J Clin Invest 2016;126:1163-72

147. Naito Y, Yoshioka Y, Yamamoto Y, et al. How cancer cells dictate their microenvironment: present roles of extracellular vesicles. Cell Mol Life Sci 2017;74:697-713.

148. Braicu C, Tomuleasa C, Monroig P, et al. Exosomes as divine messengers: are they the Hermes of modern molecular oncology? Cell Death Differ 2015;22:34-45.

149. Greening DW, Gopal SK, Mathias RA, et al. Emerging roles of exosomes during epithelial-mesenchymal transition and cancer progression. Semin Cell Dev Biol 2015;40:60-71.

150.An T, Qin S, Xu Y, et al. Exosomes serve as tumour markers for personalized diagnostics owing to their important role in cancer metastasis. J Extracell Vesicles 
$2015 ; 4: 27522$.

151.Zhang X, Yuan X, Shi H, et al. Exosomes in cancer: small particle, big player. J Hematol Oncol 2015;8:83.

152. Becker A, Thakur BK, Weiss JM, et al. Extracellular Vesicles in Cancer: Cell-to-Cell Mediators of Metastasis. Cancer Cell 2016;30:836-48.

153. Peinado H, Zhang H, Matei IR, et al. Pre-metastatic niches: organ-specific homes for metastases. Nat Rev Cancer 2017;17:302-17.

154. Bach DH, Hong JY, Park HJ, et al. The role of exosomes and miRNAs in drug-resistance of cancer cells. Int J Cancer 2017;141:220-30.

155.Li W, Li C, Zhou T, et al. Role of exosomal proteins in cancer diagnosis. Mol Cancer 2017;16:145.

156. Maia J, Caja S, Strano Moraes MC, et al. ExosomeBased Cell-Cell Communication in the Tumor Microenvironment. Front Cell Dev Biol 2018;6:18.

157.Willms E, Cabañas C, Mäger I, et al. Extracellular Vesicle Heterogeneity: Subpopulations, Isolation Techniques, and Diverse Functions in Cancer Progression. Front Immunol 2018;9:738.

158.Xu R, Rai A, Chen M, et al. Extracellular vesicles in cancer - implications for future improvements in cancer care. Nat Rev Clin Oncol 2018;15:617-38.

159. Mashouri L, Yousefi H, Aref AR, et al. Exosomes: composition, biogenesis, and mechanisms in cancer metastasis and drug resistance. Mol Cancer 2019;18:75.

160. Abd Elmageed ZY, Yang Y, Thomas R, et al. Neoplastic reprogramming of patient-derived adipose stem cells by prostate cancer cell-associated exosomes. Stem Cells 2014;32:983-97.

161. Minciacchi VR, Spinelli C, Reis-Sobreiro M, et al. MYC Mediates Large Oncosome-Induced Fibroblast Reprogramming in Prostate Cancer. Cancer Res 2017;77:2306-17.

162. Castellana D, Zobairi F, Martinez MC, et al. Membrane microvesicles as actors in the establishment of a favorable prostatic tumoral niche: a role for activated fibroblasts and CX3CL1-CX3CR1 axis. Cancer Res 2009;69:785-93.

163. Webber JP, Spary LK, Sanders AJ, et al. Differentiation of tumour-promoting stromal myofibroblasts by cancer exosomes. Oncogene 2015;34:290-302.

164. Chowdhury R, Webber JP, Gurney M, et al. Cancer exosomes trigger mesenchymal stem cell differentiation into pro-angiogenic and pro-invasive myofibroblasts. Oncotarget 2015;6:715-31.

165. Morello M, Minciacchi VR, de Candia P, et al. Large oncosomes mediate intercellular transfer of functional
microRNA. Cell Cycle 2013;12:3526-36.

166. McAtee CO, Booth C, Elowsky C, et al. Prostate tumor cell exosomes containing hyaluronidase Hyal1 stimulate prostate stromal cell motility by engagement of FAKmediated integrin signaling. Matrix Biol 2019;78-79:165-79.

167. Santi A, Caselli A, Ranaldi F, et al. Cancer associated fibroblasts transfer lipids and proteins to cancer cells through cargo vesicles supporting tumor growth. Biochim Biophys Acta 2015;1853:3211-23.

168. Josson S, Gururajan M, Sung SY, et al. Stromal fibroblastderived miR-409 promotes epithelial-to-mesenchymal transition and prostate tumorigenesis. Oncogene 2015;34:2690-9.

169.Zhao H, Yang L, Baddour J, et al. Tumor microenvironment derived exosomes pleiotropically modulate cancer cell metabolism. Elife 2016;5:e10250.

170.Inder KL, Ruelcke JE, Petelin L, et al. Cavin-1/PTRF alters prostate cancer cell-derived extracellular vesicle content and internalization to attenuate extracellular vesicle-mediated osteoclastogenesis and osteoblast proliferation. J Extracell Vesicles 2014;3.

171. Ye Y, Li SL, Ma YY, et al. Exosomal miR-141-3p regulates osteoblast activity to promote the osteoblastic metastasis of prostate cancer. Oncotarget 2017;8:94834-49.

172.Hashimoto K, Ochi H, Sunamura S, et al. Cancersecreted hsa-miR-940 induces an osteoblastic phenotype in the bone metastatic microenvironment via targeting ARHGAP1 and FAM134A. Proc Natl Acad Sci USA 2018;115:2204-9.

173. Dai J, Escara-Wilke J, Keller JM, et al. Primary prostate cancer educates bone stroma through exosomal pyruvate kinase M2 to promote bone metastasis. J Exp Med 2019;216:2883-99.

174.Angelucci A, D’Ascenzo S, Festuccia C, et al. Vesicleassociated urokinase plasminogen activator promotes invasion in prostate cancer cell lines. Clin Exp Metastasis 2000;18:163-70.

175. Fedele C, Singh A, Zerlanko BJ, et al. The $\alpha v \beta 6$ integrin is transferred intercellularly via exosomes. J Biol Chem 2015;290:4545-51.

176. Schlaepfer IR, Nambiar DK, Ramteke A, et al. Hypoxia induces triglycerides accumulation in prostate cancer cells and extracellular vesicles supporting growth and invasiveness following reoxygenation. Oncotarget 2015;6:22836-56.

177.Soekmadji C, Riches JD, Russell PJ, et al. Modulation of paracrine signaling by CD9 positive small extracellular 
vesicles mediates cellular growth of androgen deprived prostate cancer. Oncotarget 2016;8:52237-55.

178. Read J, Ingram A, Al Saleh HA, et al. Nuclear transportation of exogenous epidermal growth factor receptor and androgen receptor via extracellular vesicles. Eur J Cancer 2017;70:62-74.

179.El-Sayed IY, Daher A, Destouches D, et al. Extracellular vesicles released by mesenchymal-like prostate carcinoma cells modulate EMT state of recipient epithelial-like carcinoma cells through regulation of AR signaling. Cancer Lett 2017;410:100-11.

180.Lundholm M, Schröder M, Nagaeva O, et al. Prostate tumor-derived exosomes down-regulate NKG2D expression on natural killer cells and CD8+ T cells: mechanism of immune evasion. PLoS One 2014;9:e108925.

181. Guan H, Peng R, Fang F, et al. Tumor-associated macrophages promote prostate cancer progression via exosome-mediated miR-95 transfer. J Cell Physiol 2020;235:9729-42.

182. Corcoran C, Rani S, O’Brien K, et al. Docetaxel-resistance in prostate cancer: evaluating associated phenotypic

Cite this article as: Hatano K, Fujita K. Extracellular vesicles in prostate cancer: a narrative review. Transl Androl Urol 2021;10(4):1890-1907. doi: 10.21037/tau-20-1210 changes and potential for resistance transfer via exosomes. PLoS One 2012;7:e50999.

183. Corcoran C, Rani S, O'Driscoll L. miR-34a is an intracellular and exosomal predictive biomarker for response to docetaxel with clinical relevance to prostate cancer progression. Prostate 2014;74:1320-34.

184. Bhagirath D, Yang TL, Tabatabai ZL, et al. BRN4 Is a Novel Driver of Neuroendocrine Differentiation in Castration-Resistant Prostate Cancer and Is Selectively Released in Extracellular Vesicles with BRN2. Clin Cancer Res 2019;25:6532-45.

185. Saari H, Lázaro-Ibáñez E, Viitala T, et al. Microvesicleand exosome-mediated drug delivery enhances the cytotoxicity of Paclitaxel in autologous prostate cancer cells. J Control Release 2015;220:727-37.

186.Pi F, Binzel DW, Lee TJ, et al. Nanoparticle orientation to control RNA loading and ligand display on extracellular vesicles for cancer regression. Nat Nanotechnol 2018;13:82-9.

187.Fais S, O’Driscoll L, Borras FE, et al. Evidence-Based Clinical Use of Nanoscale Extracellular Vesicles in Nanomedicine. ACS Nano 2016;10:3886-99. 